\title{
Secondary abdominal pregnancy following rupture of bicornuate uterus in early third trimester: a case report and review of literature
}

\author{
Rajshree D. Katke*, Jyoti Raina
}

\begin{abstract}
Department of Obstetrics \& Gynaecology, Cama \& Albless Hospital, Govt. Grant Medical College, Mumbai, Maharashtra, India
\end{abstract}

Received: 14 June 2013

Accepted: 29 June 2013

*Correspondence:

Dr. Rajshree D. Katke,

E-mail: drrajshreekatke@yahoo.com

(C) 2013 Katke RD et al. This is an open-access article distributed under the terms of the Creative Commons Attribution Non-Commercial License, which permits unrestricted non-commercial use, distribution, and reproduction in any medium, provided the original work is properly cited.

\section{ABSTRACT}

Rupture uterus in a nulliparous woman is generally associated with mullerian anomalies and can present with acute obstetric emergency. It is a rare event and generally occurs in first or second trimester. Rupture of rudimentary horn in third trimester is extremely rare and can have adverse outcome for both mother and foetus. We describe a 24 years old primigravida patient with 28 weeks of gestation who came to casualty in gasping condition. She was having acute abdominal pain and distension with circulatory shock. Patient was immediately intubated and resuscitative measures started in casualty. Clinical and ultrasound findings suggestive of abdominal pregnancy and possibility of rupture of one horn of bicornuate uterus with haemoperitoneum. As patient was very critical resuscitative measures started and immediate laparotomy revealed abdominal pregnancy with dead foetus and ruptured right rudimentary horn with part of placenta adherent to omentum which was excised along with excision of rudimentary horn and placenta. Timely laparotomy with aggressive resuscitative measures saved the patients life. This case is extremely rare presentation of abdominal pregnancy in early third trimester and highlights the importance of early diagnosis of abdominal pregnancies and its timely management.

Keywords: Abdominal pregnancy, Bicornuate uterus, Haemorrhage, Pregnancy in rudimentary horn

\section{INTRODUCTION}

Abdominal pregnancy is a rare obstetric event, but one that represents a grave risk to the health of pregnant woman. It can present as catastrophic condition leading to maternal morbidity and mortality. Abdominal pregnancy is a condition in which the conceptus develops in the abdominal cavity after being extruded from the fimbriated end of the fallopian tube or through a defect in the tube or uterus. The placenta gets implanted on the abdominal parietal or visceral peritoneum, omentum or the bowel and it adheres so firmly to these structures that complete removal is seldom possible. In very rare cases of uterine rupture the foetus may be extruded into the peritoneal cavity while the placenta remains functional within the uterus and the gestation continues as a uteroabdominal pregnancy. ${ }^{1}$ Approximately $1 \%$ of all pregnancies are extrauterine and $1-3 \%$ of these are peritoneal implantations. ${ }^{2}$ The maternal mortality rate is 0.5 to $18 \%$ and perinatal mortality rate ranges between $40 \%$ to $95 \%{ }^{3}$ The maternal mortality and morbidity rates are very high especially if the condition is not diagnosed and managed at appropriate time. Advanced abdominal pregnancy is defined as pregnancy which is past 20 weeks of gestation and is associated with high foetal and maternal morbidity and mortality. It generally does not reach up to term and usually the end result is the extraction of a dead foetus, however live births have been reported. Abdominal pregnancy usually occurs after tubal abortion or rupture and less often from subsequent implantation with in the abdomen following rupture of a unicornuate or bicornuate uterus. Rudimentary horn pregnancy of a bicornuate uterus usually terminates in rupture during first or second trimester of pregnancy and the presentation in early third trimester is extremely rare. Herein we present a case of 28 weeks abdominal 
pregnancy following rupture of right rudimentary horn of bicornuate uterus.

\section{CASE REPORT}

A 24 years old pregnant woman was referred to our casualty in a cardiac ambulance at 28 weeks of gestation in a very morbid condition with drowsiness, gasping and hypotension. Patient a primigravida had conceived spontaneously 1 year after her marriage and had initially started with pain in lower abdomen at 12 weeks gestation for which she consulted at local hospital where she was managed conservatively with analgesics and antibiotics and was discharged after her pain got subsided. At 22 weeks of gestation, patient again had severe lower abdominal pain and vomiting. There was no bleeding per vaginum. She got admitted in a local hospital where ultrasonography was done which revealed bicornuate uterus with a single live gestation of 22 weeks. She was managed with intravenous fluids and analgesics and was discharged. Again at 28 weeks of gestation, at home, patient had severe agonizing lower abdominal pain, several episodes of vomiting and giddiness. She was immediately rushed to same hospital where her condition further deteriorated and was finally referred to our hospital. On arrival, patient was gasping, tachypnoeic and in altered sensorium. There was marked pallor, extremities were cold and clammy, pulse was feeble and blood pressure was not recordable. Abdomen was distended and tense. Uterine size could not be made out, foetal heart sound was not audible. Patient was immediately intubated and rushed to operation theatre. Blood transfusion was immediately started. Quick pelvic examination revealed fullness in the fornices with cervical movement tenderness. There was no bleeding per vaginum. Urgent bedside ultrasonography revealed fetus lying outside uterus in abdomen with no cardiac activity with echogenic free fluid in the abdominal cavity. Uterus was bicornuate Ultrasound guided tap revealed frank bloody aspirate. Provisional diagnosis of rupture of one horn of bicornuate uterus with haemoperitoneum and resultant haemorrhagic shock with doubtful viability of foetus was made. An emergency laparotomy was done with continuing resuscitative measures. After opening the abdomen, a dead fetus of $1.2 \mathrm{~kg}$ was lying in the abdominal cavity with umbilical cord attached to the placenta which was adherent to the ruptured right rudimentary horn. There was profuse bleeding from the rupture site the bleeding points were immediately clamped and ligated. The abdominal cavity was full of blood clots weighing around $1 \mathrm{~kg}$ with free blood around 3.5 liters which was removed. Cord clamped cut and ligated fetus taken out. Major bulk of the placenta was morbidly adherent to this ruptured right rudimentary horn of uterus. However some part of the placenta was implanted on omentum which was necrotic and was excised. Placenta could not be separated from right rudimentary horn so right rudimentary horn of uterus along with placenta was excised. The left horn which appeared to be normal, both the fallopian tubes and both the ovaries preserved for the future reproductive functions. After achieving proper haemostasis, instrument counts and peritoneal toileting abdomen was closed back in layers. Five pints of whole blood and 5 pints of fresh frozen plasma were transfused. Patient had an uneventful recovery and was discharged on $9^{\text {th }}$ post-operative day. Advise for contraception given for 6 months. The timely aggressive resuscitative measures and a good surgical expertise saved the precious life of patient.

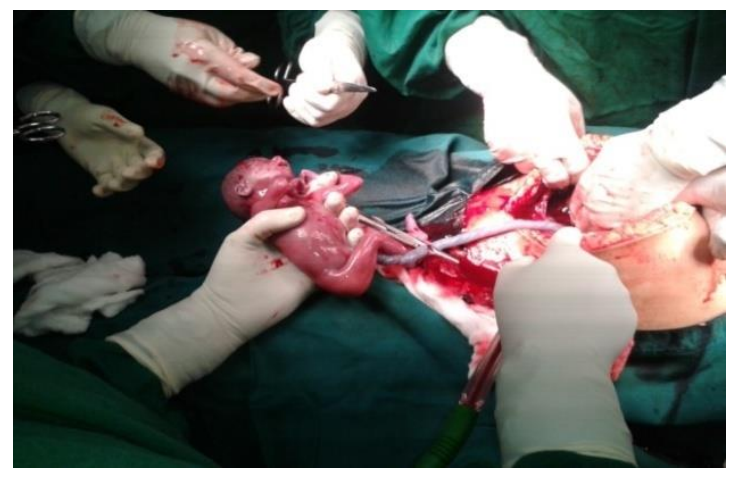

Figure 1: Foetus was lying in the abdominal cavity which taken out from abdominal cavity.

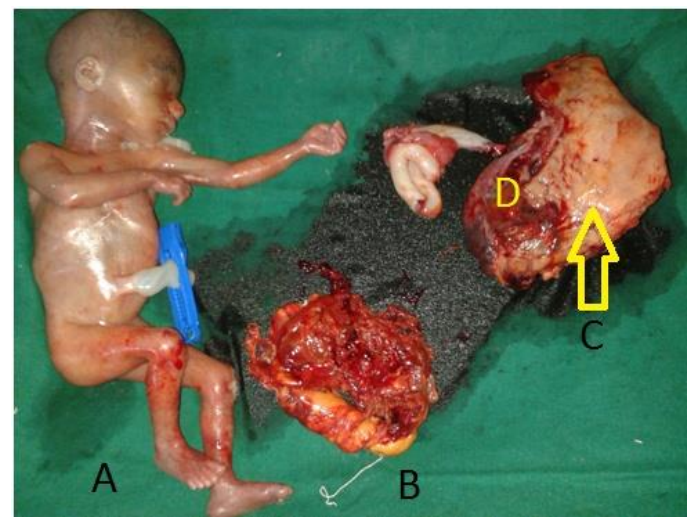

Figure 2: (A) Dead foetus $1.2 \mathrm{Kg}$, (B) Excised Omentum, (C) Rupture right rudimentary horn, (D) Umbilical cord with placenta adherent to the right rudimentary horn.

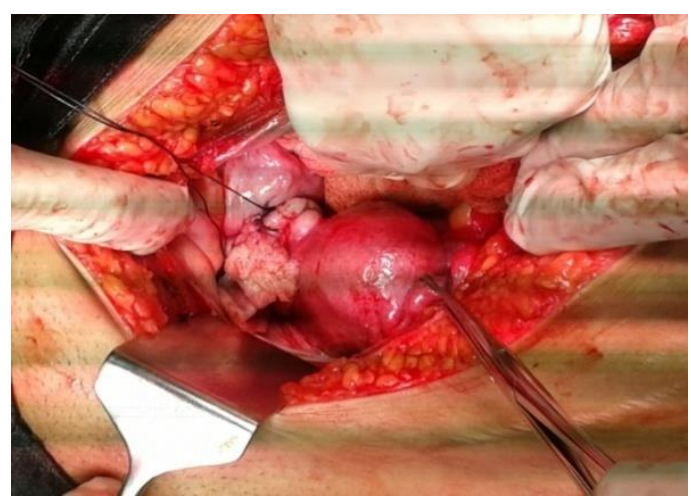

Figure 3: Preserved left uterine horn with both fallopian tubes and ovaries. 


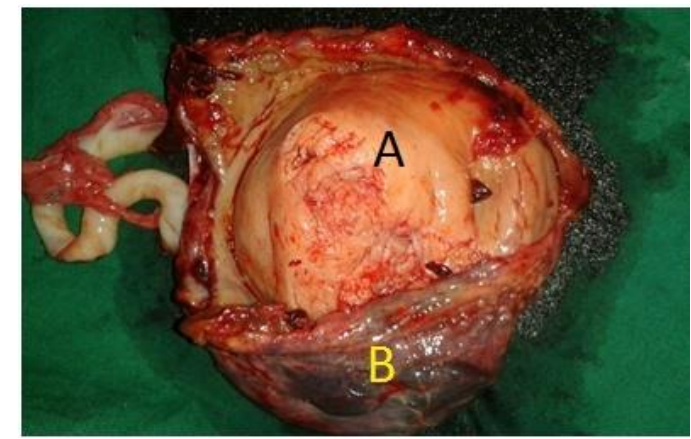

Figure 4: (A) Ruptured right horn of uterus, (B) Adherent placenta.

\section{DISCUSSION}

Pregnancy in a bicornuate uterus is usually considered high risk and requires extra monitoring because of association with poor obstetric outcome. Bicornuate uterus results due to failure of fusion of mullerian ducts or sometimes lower part of the ducts fuse leaving the cornua separate. The cervix and vagina may be single or double. The prevalence of mullerian duct malformations in the general population and in the population of fertile women is estimated to be $4.3 \%$ and in the infertile patients approximately $25 \%$. Septate uterus is the commonest anomaly with a mean incidence of approximately $35 \%$ followed by bicornuate uterus which is approximately $25 \%$ and arcuate uterus approximately $20 \%{ }^{4}$ These malformations remain asymptomatic till the patient reaches reproductive age. Such anomalies are reported to result in increased rate of infertility, miscarriage, recurrent pregnancy loss, preterm labour and other obstetric complications. Clinical presentation varies from being asymptomatic to vague complaints of mild lower abdominal pain with gastrointestinal upset and finally to its severest form of acute abdomen with haemorrhagic shock. The most significant threat of a rudimentary horn pregnancy is the risk of rupture because of poorly developed musculature. In bicornuate uterus if pregnancy occurs in the well developed horn, it continues normally and only in cases where conception occurs in the rudimentary horn does danger need to be anticipated. ${ }^{5}$ Pregnancy in rudimentary horn occurs in approximately $1 / 76000$ to $1 / 150000$ pregnancies. ${ }^{6,7}$ Rupture of uterine horn occurs because of inability of the malformed uterus to expand with increasing gestational age. Timing of rupture varies from 15 to 35 weeks depending on horn musculature and its ability to hypertrophy and dilate. $70 \%$ to $90 \%$ of ruptures occur before 20 weeks and can be catastrophic. ${ }^{8}$ Few cases may reach late second trimester. Chang et al reported rupture of the rudimentary horn as late as 25 weeks of gestation. ${ }^{9}$ In our case rupture occurred at early third trimester. First case of uterine rupture associated with rudimentary horn was reported in 1669 by Mauriceau. ${ }^{10}$ A case of advanced secondary abdominal pregnancy through a small rent in rudimentary horn was reported by Desai et al. ${ }^{11}$ Early diagnosis of the condition is essential but can be challenging. Fedele et al found ultrasonography to be useful in the diagnosis but sensitivity decreases as the pregnancy advances. ${ }^{12}$ MRI has also been used with success to diagnose abdominalpregnancy. ${ }^{13}$ The extent of placental invasion, its relationship to the pelvic organs and the vascular supply could be more closely visualised by magnetic resonance imaging. ${ }^{14}$ There is no definitive clinical criteria to detect this life threatening condition and diagnosis can be quite difficult because of enlarging horn with thinned myometrium can obscure the adjacent anatomic structures. Nonetheless, in developing countries most of the cases remain undiagnosed until it ruptures and presents as obstetric emergency. Abdominal pregnancies should be interrupted at diagnosis, as the potential for delivering of a healthy infant is poor and the risk of maternal complications is high. However if the diagnosis is made late in pregnancy, a viable infant may be delivered via laparotomy. Thus expectant management to gain foetal maturity has been attempted and has been successful in only few cases. ${ }^{15}$ In our case the rupture of rudimentary horn pregnancy occurred at 28 weeks, however in literature after the search we found that most of the cases published are up to $20^{\text {th }}$ weeks of gestation hence it appears to be unique case. As this patient came to casuality in a critical state of gasping. The timely aggressive resuscitative measures, a good surgical expertise, high risk consent of grade 5 anaesthesia given by the patient's relative to go ahead with the surgery even though there was a high risk. All these efforts have revived the patient from her very critical condition.

\section{CONCLUSION}

It is imperative for every obstetrician to have in mind the possibility of abdominal pregnancy in cases of rudimentary horn with pain in abdomen. However it still remains a diagnostic and therapeutic challenge when such patients come in acute emergency. Despite considerable improvement in technical abilities, prenatal diagnosis remains elusive in the developing countries resulting in delays in diagnosis and decision making. Timely laparotomy in haemodynamically unstable patients with proper resuscitative measures will definitely help the patient. Pregnancy in an anomalous uterus is a high risk entity, with good clinical acumen one can observe the right course of pregnancy and intervention as if required in such critical emergency the key factor in the management is The immediate replacement of blood \& blood products can replace the blood loss in the body\& reverse the condition of haemorrhagic shock before it goes to the state of irreversible stage of shock at the same time one should give emphasis on the right surgical treatment to control the bleeding which can reduce the mortality and morbidity of the patient.

\section{REFERENCES}

1. Cunningham FG, MacDonald PC, et al, editors. Williams obstetrics, 19th ed. New Jersey: PrenticeHall International Inc; 1993. pp. 543-53. 
2. Parekh VK, Bhatt S,Dogra VS. Abdominal pregnancy: An unusual presentation. JUM, 2008,27(4):679-681.

3. Strafford JC, Ragan WD. Abdominal pregnancy. Review of current management. Obstet Gynecol. 1977 Nov;50(5):548-52.

4. Grimbizis GF, Camus M, Tarlatzis BC, Bontis JN, Devroey P. Clinical implications of uterine malformationsand hysteroscopic treatment results. Hum. Reprod. Update 2001; 7:161-174.

5. Whitehouse B. Rupture of pregnant rudimentary horn of bicornuate uterus. Proc R Soc Med 1912; 5: 121-124.

6. Ural SH, Artal R. Third trimester rudimentaryhorn pregnancy. A case report. J Reprod Med1998; 37: 919-921.

7. Nahum GG. Rudimentary uterine horn pregnancy. A case report on surviving twins delivered eightdays apart. J Reprod Med 1997;42:525-532.

8. O`leary JL, O`leary JA. Rudimentry horn pregnancy. Obstetrics and Gynaecology1963;22:371-374.

9. Chang JC, Lin YC. Rupture of rudimentary horn pregnancy. Acta Obstet Gynecol Scand 1992;71:235238.
10. Mauriceau F, Traite. Des. maladaies des femmes grosses, Compaigne des Libraries Paris, France Vol $1 ; 6^{\text {th }}$ ed. $1721: 86$.

11. Desai BR, Patted SS, Pujar YV, et al. Advanced secondary abdominal pregnancy following rupture of rudimentary horn. J Obstet Gynecol India 2005;55:180.

12. Fedele L, Dorta M, Vercellini P, Brioschi D, Candiani GB. Ultrasound in the diagnosis of subclasses of unicornuate uterus. Obstet Gynaecol 1988;71(2):274-277.

13. Dahiya K, Sharma D. Advanced abdominal pregnancy; A diagnostic and management dilemma. J Gynecol Surg 2007;23(2):69-72.

14. Ozeren S, Caliskan E, Corakci A, Ozkan S, Demirci A. Magnetic resonance imagingand angiography for the prerupture diagnosis of rudimentary uterine horn pregnancy. Acta Radiol 2004;45:878-881.

15. Beddock R, Naepels P, Gondry C, et al. Diagnosis and current concepts of management of advanced abdominal pregnancy. Gynecol Obstet Fertil 2004;32:55.

DOI: $10.5455 / 2320-1770 . i j r \operatorname{cog} 20130944$

Cite this article as: Katke RD, Raina J. Secondary abdominal pregnancy following rupture of bicornuate uterus in early third trimester: a case report and review of literature. Int J Reprod Contracept Obstet Gynecol 2013;2:454-7. 